\title{
Role of Aircraft Feedback Information in Developing Maintainability Allocation Index
}

\author{
W. M. S. Wan Husain
}

\begin{abstract}
This paper present attempt to utilise aircraft maintenance historical data and information and author termed as Aircraft feedback information systems. Aircraft feedback information contains various types of information that could be used for future improvement rather than just the failure elements. Literature shows that feedback information reports have helped to identify the critical and sensitive components that need more attention for further improvement. This paper consists of two elements. The first element is to present different types of Aircraft feedback information and the second element is a methodology in developing the processes of maintainability allocation. The study shows that the aircraft maintenance related feedback information systems analyses were very useful for deciding maintainability effectiveness; these include planning, organising maintenance and design improvement. There is no doubt that the combinations between the historical data information and maintainability allocation have the ability to contribute an important role in design activities. The results also show that maintainability is an importance measure that can be used as a guideline for managing efforts made for the improvement of aircraft components.
\end{abstract}

Index Terms-Aircraft maintenance, aircraft information systems, historical data, maintainability allocation.

\section{INTRODUCTION}

One of the value drivers in civil aircraft industry is aircraft maintenance. The maintenance through prediction methodology has very often been seen as one of the potential areas where maintenance effectiveness targets can be easily and quickly achieved. This can be achieved through an understanding of historical information from previous designs and feedback information supplied by aircraft mechanics, engineers and/or aviation regulators. There are many types of aircraft related historical data available to be collected, compiled and analysed for future improvement. The idea is to ensure that occurrences do not happen again as well as to ensure the element of safety is improved. Failure rate $(\lambda)$ is one piece of historical information and for many years failure rates $(\lambda)$ were important elements used to predict maintainability effectiveness. The purpose of the paper is sharing some elements of maintainability evaluation as well to highlight the opportunities to improve the existing scenario such as the opportunities for closing the identified gaps and/or problems.

Manuscript received May 19, 2015; revised August 15, 2015.

W. M. S. Wan Husain is with the Aerospace Section, Universiti Kuala Lumpur, Malaysian Institute of Aviation Technology (UniKL MIAT), 43800 Dengkil. Selangor. Malaysia (e-mail: sufian@unikl.edu.my).

\section{FEEDBACK INFORMATION}

The maintainability prediction can be facilitated by systematically utilising the feedback information from past and current in-service aircraft. Learning from the past and existing experiences offers numerous opportunities for improvement and particularly a reduction in maintenance cost and errors. Therefore it is important that all relevant, existing and current feedback information is systematically collected, compiled, analysed and validated appropriately, so that necessary actions and decisions can be made. This collected information is referred to as feedback information.

The importance of aircraft related feedback information has been detected by the Boeing Company. This has been transformed into several approaches, some of which are known as the In Service Data Program (ISDP) [1] and the Flight Recorder Data Service (FRDS) [2] which provide effective information quickly and check maintenance needs. These approaches show that feedback information is valuable for further availability preparation. This indication offers the opportunity for future design methodology improvement. The important of feedback is also has been described in detail by UK CAA [3].

Feedback information can be utilised to improve future product development as well as safety. These data are also used to determine maintenance activities [4]. The trends and behaviour of previous and/or existing products are analysed and therefore assist with appropriate decision-making for future improvements. This is to ensure that the determined objectives have been met. The types of information collected are the failure types, failure modes and frequencies of failure, and/or replacement and maintenance trends. The information is then evaluated and used to answer the following common questions, such as 'Where are we now?', 'What should we do now?', 'Why has this happened?' and 'How can we improve this situation?'.

There are also several researchers have been carried related to human factors utilizing feedback, such as Maintenance Error Decision Analyses (MEDA). Maintenance Error Decision Aid (MEDA) was developed to determine "the factors that contribute to maintenance errors and taking corrective actions to eliminate or reduce the probability of future, similar errors" [5]. The process in MEDA consists of five stages: event, decision, investigation, prevention, and feedback [6]. In terms of design, there is much information that can be used by the designer at the design stage, which could also lead to future error reduction. Another source of feedback is known as Maintenance Error Management Systems (MEMS) and described in CAA Airworthiness Notice 71 . The aim is to understand and 
examine what and why an event happened. The objective is "to identify the factors contributing to incidents and to make the system resistant to similar errors" [7]. The aim is not restricted to knowledge of what happened, but also to solve why it happened, and thus offer opportunities to minimise recurrence. Based on the study, there 4 main elements of the feedback information system, namely Product Development, Design for X, Aircraft feedback Information systems, and Existing Maintainability Prediction methodologies [8]. Overall, the feedback information system can be categories into four main elements and described below.

\section{A. Designer Perspective}

At this level, the perspective of maintainability should be improved at the design stage where all required information should be supplied to the respective department such as Engineering or Design. The information supplied should be specific to the problems that have arisen or to the specific required improvements. This is because the designer does not have time to evaluate the whole set of reports from the customer or the end user (i.e. Maintenance Engineer, Mechanic and Pilot). In the aviation industry, there are many feedback mechanisms developed to obtain as much information as possible from the end user in order to improve the existing designed of products or systems. The information is also used to reduce human error, improve the maintenance time interval, and to set a benchmark for the future trend of products or systems to be designed.

\section{B. Historical Data and Information Perspective}

To ensure that the improvement of a new design offers additional benefits to those previously provided, historical data should be utilised. Collectively, historical data and information are capable of providing a better understanding for better design improvement and, consequently, be able to offer other benefits such as both cost and human error reductions. There are different types of historical data available from reliable sources. Based on the literature review, there are more than ten types of reliable sources of information [8]. Some sources of information such as Airworthiness Directive (AD) are controlled by regulatory bodies (i.e. FAA \& CAA).

Furthermore, this paper presents on sources of information that can be used as alternatives to predict maintainability effectiveness. The Service Difficulty Reporting System (SDRS) is the most appropriate source of information that is suitable for this research. Most of the information included in the SDRS contains information that is useful to the designer when considering improvements such as part conditions, nature of conditions, stage of operations, aircraft types, aircraft model, and precautionary actions. These elements should be able to offer a clear indication to the aircraft designer that the data have been analysed appropriately, accurately and systematically. In this research, the SDR data were collected from reliable sources and were analysed systematically to ensure the most reported service difficulties are followed by improvement in terms of maintainability prediction.

\section{Maintenance Perspective}

This level is referred to as the end user of designing products or systems. Almost all the valuable information for future products improvement is supplied from this level. This is because at this level, each person is not only performing his/her duties according to the requirements, but they are also putting their ideas or theories of design into a practical form.

\section{Quantitative Perspective}

After reviewing each element from the MIL-HDBK-472 checklists, the highest score is allocated to the maintenance task needing minimum effort to be performed. Other than that the fewest tools, or no tools, required to perform the maintenance tasks will also be awarded the highest score.

\section{MAINTAINABILITY ALLOCATION}

Maintainability Allocation is a process to identify the allowable maximum task time for each individual component. Consequently, this provides clear pictures to the designers to design and identify potential design improvement within allowable maintenance allocation time limits. The rationale of the development of a maintainability allocation method led to the expansion of an existing maintainability allocation methodology through inserting several new modules and new score values to allocate task times specifically for mechanical aircraft components. The first step in this analysis was to try to find a correlation between allocation maintainability score values used by Chipchak [9] and other measures. Once this relationship had been established, the score values could be calculated for new module types and added to the list of allocation methods. The development of methodology begins with identifying a methodology for assigning scores values by using the existing list, as shown in Table I.

The first approach was to use the failure rate and the results are shown in Fig. 1. The values of the failure rate are collected by using an NPRD data set [10]. Results show a trend of failure rates that are not consistent with the score values.

TABLE I: IDENTIFYING SCORE VALUE METHODOLOGY - APPROACH 1
\begin{tabular}{|r|l|c|c|}
\hline No & \multicolumn{1}{|c|}{ Module [9] } & $\begin{array}{c}\text { Score } \\
{[9]}\end{array}$ & $\begin{array}{c}\lambda \text { (per millions) } \\
{[10]}\end{array}$ \\
\hline 1 & Lights & 1 & $7.26 \mathrm{E}-05$ \\
\hline 2 & Digital & 1 & $2.04 \mathrm{E}-05$ \\
\hline 3 & Low-level analogue & 1.5 & $6.00 \mathrm{E}-06$ \\
\hline 4 & High-level analogue & 1.5 & $6.00 \mathrm{E}-06$ \\
\hline 5 & Digital Computers & 2 & $1.55 \mathrm{E}-05$ \\
\hline 6 & Power Supplies & 2 & $1.55 \mathrm{E}-05$ \\
\hline 7 & Electromechanical equipment & 3 & $3.00 \mathrm{E}-06$ \\
\hline 8 & $\begin{array}{l}\text { High-power/high-frequency } \\
\text { components }\end{array}$ & 4 & $2.74 \mathrm{E}-05$ \\
\hline 9 & Interconnections & 4 & $5.23 \mathrm{E}-05$ \\
\hline 10 & Air conditioners & 4 & $5.08 \mathrm{E}-04$ \\
\hline 11 & Liquid coolant systems & 4 & $6.57 \mathrm{E}-04$ \\
\hline 12 & Mechanical Structures & 6 & $1.60 \mathrm{E}-08$ \\
\hline 13 & Rotating mechanism/engines & 10 & $1.75 \mathrm{E}-04$ \\
\hline
\end{tabular}

A second attempt made was using the task time approach. All the task time values were predicted by using MIL-HDBK-472, Procedure III. The author performed maintenance task time estimation for the removal and reassembly of each component by using the MIL-HDBK-472, 
Procedure III maintainability prediction method. The outcomes of the estimation are shown in Table II. The outcomes have shown some good indications compared to the first approach. By looking at the minutes or hour values as shown in Fig. 2, the results show consistent values compared to the existing score values. As the task times increased, the score values also increased.

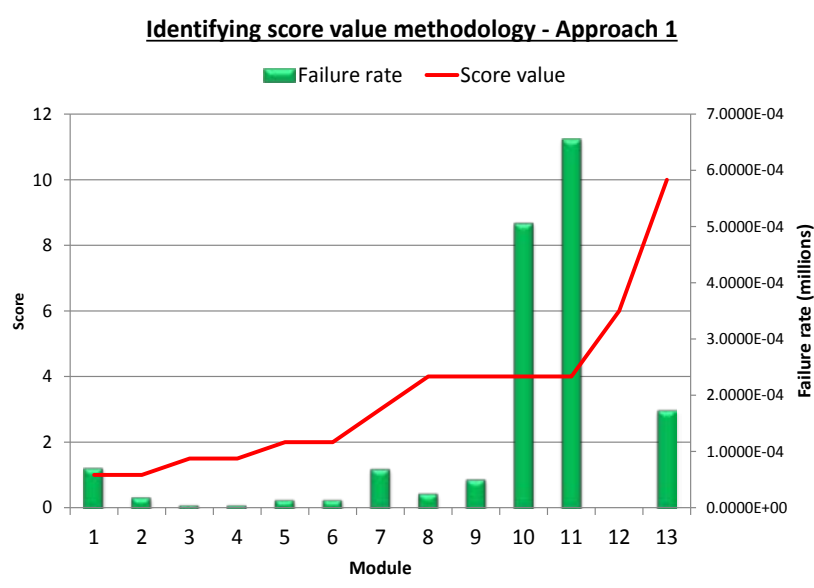

Fig. 1. The trend of failure rates.

TABLE II: IDENTIFYING SCORE VALUES METHODOLOGY - APPROACH 2

\begin{tabular}{|c|l|c|c|c|}
\hline No & \multicolumn{1}{|c|}{ Module [9] } & Minutes & Hour & $\begin{array}{c}\text { Score } \\
{[9]}\end{array}$ \\
\hline 1 & Lights & 8.86 & 0.15 & 1 \\
\hline 2 & Digitals & 31.89 & 0.53 & 1 \\
\hline 3 & Low-level analogue & 31.89 & 0.53 & 1.5 \\
\hline 4 & High-level analogue & 31.89 & 0.53 & 1.5 \\
\hline 5 & Digital Computers & 22.66 & 0.38 & 2 \\
\hline 6 & Power Supplies & 20.18 & 0.34 & 2 \\
\hline 7 & $\begin{array}{l}\text { Electromechanical } \\
\text { equipment }\end{array}$ & 64.45 & 1.07 & 3 \\
\hline 8 & $\begin{array}{l}\text { High-power/High-Frequ } \\
\text { ency components }\end{array}$ & 48.64 & 0.81 & 4 \\
\hline 9 & Interconnections & 40.61 & 0.68 & 4 \\
\hline 10 & Air Conditioners & 60.41 & 1.01 & 4 \\
\hline 11 & Liquid coolant system & 67.82 & 1.13 & 4 \\
\hline 12 & Mechanical Structures & 79.20 & 1.32 & 6 \\
\hline 13 & $\begin{array}{l}\text { Rotating } \\
\text { Mechanism/Engines }\end{array}$ & 368.84 & 6.15 & 10 \\
\hline
\end{tabular}

Identifying score value methodology - Approach 2

Task time (hour) - Score value

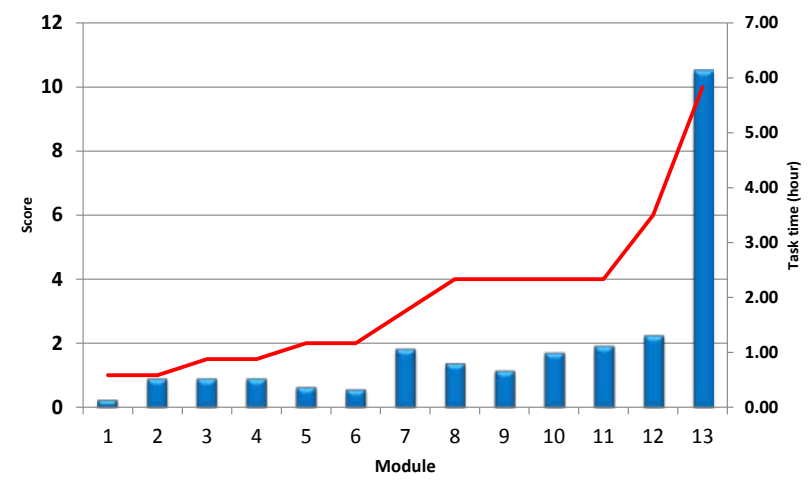

Fig. 2. Identifying score value methodology - Approach 2.

Once the general correlation had been established the following trendlines were performed to identify the most appropriate formula to allow score values to be predicted from any given task time. To do this, the author proposed four different formulae and identified the formulae which have the closest R2 values. As a result, Fig. 3 and Table III show a summary of the evaluations.

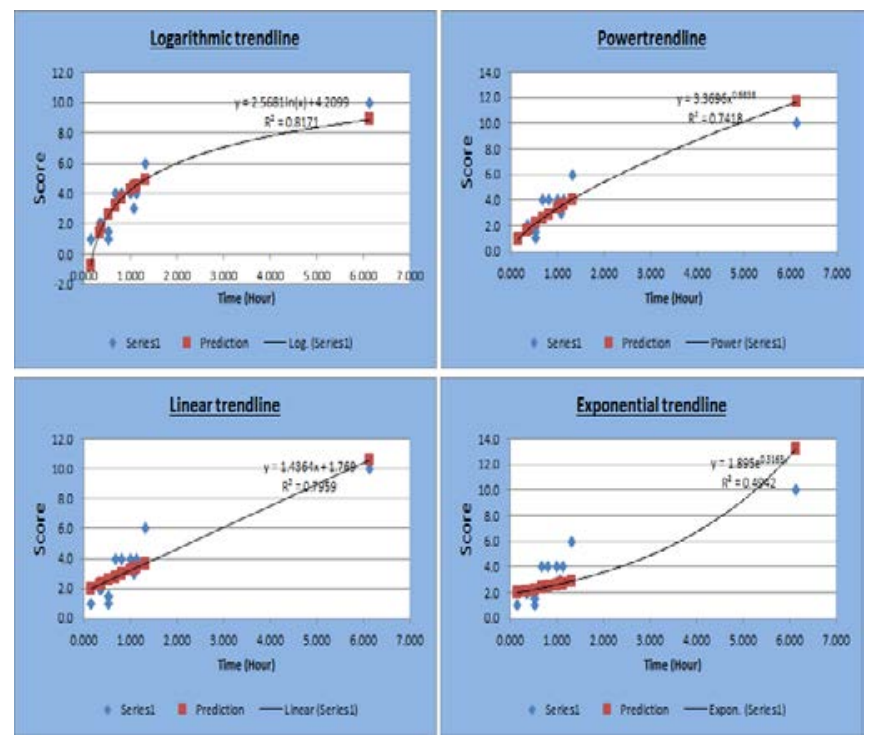

Fig. 3. Four types for trendlines and formula.

TABLE III: SUMMARY OF FOUR TYPES OF TRENDLINES AND FORMULA

\begin{tabular}{|l|l|c|}
\hline \multicolumn{1}{|c|}{ Trendline } & \multicolumn{1}{|c|}{ Formula } & $\mathbf{R}^{\mathbf{2}}$ \\
\hline Log & $\mathrm{y}=2.5681 \ln (\mathrm{x})+4.2099$ & 0.8171 \\
\hline Linear & $\mathrm{y}=1.4364 \mathrm{x}+1.769$ & 0.7959 \\
\hline Power & $\mathrm{y}=3.3696 \mathrm{x}^{0.6838}$ & 0.7418 \\
\hline Exponential & $\mathrm{y}=1.895 \mathrm{e}^{0.3163 \mathrm{x}}$ & 0.4942 \\
\hline
\end{tabular}

From this initial analysis, it can be seen that the Log and Linear trendlines provide the best $\mathrm{R} 2$ values. The selection is based on the closest R2 value to 1 . The results are quite similar so both Log and Linear have been tested. The following process was to apply the selected formula and perform testing and validation. This is to ensure the selected formulae are proven as well as applicable for this research. The testing and validation were performed by using three main case studies: 1) Aircraft Fuel System (JASC 28), 2) Aircraft Communications System (JASC 23), and 3) Aircraft Landing Gear (JASC 32). The testing and validation was performed by using predicted score values, as shown in Table IV. The "value" column shows the predicted values means while the "Round" column shows the round from the decimal. In this technique the author decided to use only the 0.5 decimals. Therefore, if the predicted value was 2.8 the "round" column result will be 3.0 .

TABLE IV: THREE TYPES OF FORMULA USED FOR TESTING AND

\begin{tabular}{|c|c|c|c|c|c|c|c|c|c|}
\hline \multicolumn{10}{|c|}{ VALIDATION } \\
\hline \multirow{3}{*}{ No } & \multirow{3}{*}{ Generic Module } & \multirow{3}{*}{$\mid \lambda^{154}$} & \multicolumn{2}{|c|}{ TASKS TIME } & \multicolumn{5}{|c|}{ SCORE } \\
\hline & & & \multirow{2}{*}{ MINUTE } & \multirow{2}{*}{ HOUR } & \multirow{2}{*}{ EXISTING } & \multicolumn{2}{|c|}{ LOGFORMULA } & \multicolumn{2}{|c|}{ LINEAR FORMULA } \\
\hline & & & & & & Value & Round & Value & Round \\
\hline 1 & Lights & 72.6227 & 8.9 & 0.15 & 1.0 & -0.7 & -1.0 & 2.0 & 2.0 \\
\hline 2 & Digital & 20.4399 & 31.9 & 0.53 & 1.0 & 2.6 & 3.0 & 2.5 & 3.0 \\
\hline 3 & Lowtevel analozue & 6.0000 & 319 & 0.53 & 1.5 & 2.6 & 3.0 & 2.5 & 3.0 \\
\hline 4 & High-level analogue & 6.0000 & 319 & 0.53 & 1.5 & 2.6 & 3.0 & 2.5 & 3.0 \\
\hline 5 & Communication & 305.9465 & 233 & 0.39 & 2.0 & 1.8 & 20 & 2.3 & 2.0 \\
\hline 6 & Digital Computers & 15.5250 & 22.7 & 0.38 & 2.0 & 1.7 & 2.0 & 2.3 & 2.0 \\
\hline 7 & Power Supplies & 15.5250 & 20.2 & 0.34 & 2.0 & 1.4 & 1.0 & 2.3 & 2.0 \\
\hline 8 & Electromechanical equipment & 71.1744 & 54.4 & 1.07 & 3.0 & 4.4 & 4.0 & 3.3 & 3.0 \\
\hline 9 & Hightpower/high-frequency components & 27.3640 & 486 & 0.81 & 4.0 & 3.7 & 4.0 & 2.9 & 3.0 \\
\hline 10 & Interconnections & 52.3040 & 40.6 & 0.68 & 4.0 & 3.2 & 3.0 & 2.7 & 3.0 \\
\hline 11 & Air conditionsers & 508.1964 & 60.4 & 1.01 & 4.0 & 4.2 & 4.0 & 3.2 & 3.0 \\
\hline 12 & Liquid coolant systems & 657.2513 & 67.8 & 1.13 & 4.0 & 4.5 & 5.0 & 3.4 & 3.0 \\
\hline 13 & Mechanical Structures & 0.0160 & 79.2 & 1.32 & 6.0 & 4.9 & 5.0 & 3.7 & 4.0 \\
\hline 14 & Mechanical Structures with Mechanism (i.e.: IG, Stablis & 1.0000 & 217.5 & 3.63 & 8.0 & 7.5 & 8.0 & 7.0 & 7.0 \\
\hline 15 & Rotating mechanism/engines & 175.4275 & 368.8 & 6.15 & 10.0 & 8.9 & 9.0 & 10.6 & 11.0 \\
\hline
\end{tabular}




\section{Other Elements in Maintainability Allocation METHODOLOGY}

The following equations are used to predict the maintainability allocation [11]

$$
\begin{gathered}
\text { Failure Rate }(\lambda)=\frac{\text { Number of Failures }}{\text { TotalOperating Time }} \\
\text { Mean Time Between Failure }(M T B F)=\frac{1}{\lambda} \\
\text { Inherent Availability }\left(A_{i}\right)=\frac{M T B F}{M T B F+M T T R} \\
\text { Mean Time to Repair }=\frac{M T B F\left(1-A_{i}\right)}{A_{i}}
\end{gathered}
$$

In this research, for some of the elements such as MTBF and Inherent Availability $\left(A_{i}\right)$, the author will only assume the values. This is because the author is only interested in and focusing on maintainability prediction and at the same time identifying the appropriate value for MTTR which will be used in maintainability allocation prediction. For the purpose of illustration, it is assumed that the landing gear systems must be designed to meet an inherent availability $\left(A_{i}\right)$ requirement of 0.9998 , an MTBF of 500 hours. Thus, the MTTR requirement is 0.1 hour as shown in calculation below.

$$
M T T R=\frac{500-(1-0.9998)}{0.9998}=0.1
$$

\section{CONCLUSION}

The main contribution from this exercise is the LINEAR formula $(y=1.4364 x+1.769)$ can be used to calculate any other potential modules. In this research, the author has proved that the mentioned formula has been used to calculate potential score value for new module. In the future more modules can be added and therefore offer accuracy in determining the allowable maximum task time for specific components.

\section{REFERENCES}

[1] T. Simpson, D. Rosen, J. Allen, and F. Mistree, "Metrics for assessing design freedom and information certainty in the early stages of design," Journal of Mechanical Design, vol. 120, no. 4, pp. 628-635, 1998.

[2] J. Kneuer, "In-service data program helps Boeing design, build, and support airplanes,” Boeing AeroMagazine, no. 29, pp. 16-21, 2008.

[3] Civil Aviation Authority, Aviation Maintenance Human Factors (JAR 145), CAP 716, UK, 2002.

[4] Boeing. (2011). Flight recorder data services (FRDS). [Online]. Available:

http://www.boeing.com/commercial/maintenance/flight_recorder_data .html

[5] W. Rankin, "The maintenance error decision aid (MEDA) process," in Proc. XIVth Triennial Congress of the International Ergonomics Association and 44th Annual Meeting of the Human Factors and Ergonomics Association, San Diego, 2000.

[6] W. Rankin, R. Hibit, J. Allen, and R. Sargent, "Development and evaluation of the maintenance error decision aid (MEDA) process," International Journal of Industrial Ergonomics, vol. 26, no. 2, pp. 261-276, 2000.

[7] Civil Aviation Authority, Civil Aircraft Airworthiness Information and Procedures (CAAIP), Ministry of Defence, UK, 2008.

[8] W. M. S. Wan Husain, "Maintainability prediction for aircraft mechanical components utilising aircraft feedback information,” Cranfield University, Bedford, 2011.

[9] J. Chipchak, "A practical method of maintainability allocation," Aerospace and Electronic Systems, IEEE Transactions, vol. AES-7, no. 4, pp. 585-589, 1971.

[10] M. David, F. William, R. John, Z. Peter, and M. Scott, "Nonelectronic parts reliability data - 2011,” Reliability Information Analysis Center (RIAC), New York, 2011.

[11] B. Blanchard, V. Dinesh, and P. Elmer, Maintainability: A Key to Effective Serviceability and Maintenance Management, New York: Wiley, 1995.

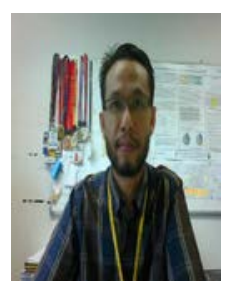

W. M. S. Wan Husain is a senior lecturer at the Malaysian Institute of Aviation Technology, Universiti Kuala Lumpur. He received his first and second diploma in product design CAD/CAM from Humber College, CANADA in 1999, his B.Sc. degree in mechanical engineering technology from University of Hartford, Connecticut, USA in 1999, his master of science in manufacturing system engineering from University Putra Malaysia, Malaysia in 2005, and Ph.D. degree in aircraft maintenance and engineering from Cranfield University in 2011. His research interests include maintainability prediction, design for $\mathrm{X}$, advanced manufacturing technology, and manufacturing system engineering. Until today, he has supervised 10 undergraduate students and 1 Ph.D. student. He has also published 9 papers and reviewed 7 papers. Dr. Wan is a member of Technological Association of Malaysia (TAM), and AFEO Associate ASEAN Engineering Technologist (AAET). 